\title{
Interactions of serum copper, selenium, and low density lipoprotein cholesterol in atherogenesis
}

\author{
Jukka TSalonen, Riitta Salonen, Kari|Seppänen, Marjatt@_ Kantola, Sirpa Suntioinen, \\ Heikki|Korpela
}

\begin{abstract}
Objective-To investigate the interactions between serum copper, selenium, and low density lipoprotein cholesterol concentrations with regard to the progression of carotid atherosclerosis.

Design-Longitudinal study of a cohort of middle aged men followed up for 24 months.

Setting-Epidemiological survey of the population of seven communities in eastern Finland.

Subjects -126 men aged $42,48,54$, or 60 at examination randomly selected from a population based sample of 2682 men.

Main outcome measures-Increase in maximal carotid intima media thickness.

Results-The mean increase in the maximal common carotid intima media thickness after two years was greater in men with high serum copper concentrations $(0.16 \mathrm{~mm}$ compared with $0.08 \mathrm{~mm}$ in men with concentrations $<\mathbf{1 7 . 6} \mu \mathrm{mol} / \mathrm{l} ; \mathrm{p}=0.010)$, those with low serum selenium concentrations $(0.15 \mathrm{~mm}$ compared with $0.09 \mathrm{~mm}$ in men with concentrations $\geqslant 1.40 \mu \mathrm{mol} / \mathrm{l} ; \mathrm{p}=\mathbf{0 . 0 3 5}$ ), and those with raised serum low density lipoprotein cholesterol concentrations $(0.15 \mathrm{~mm}$ compared with $0.08 \mathrm{~mm}$ in men with concentrations $<4.0 \mathrm{mmol} / 1 ; p=0.032$ ) after adjustment for age and cigarette pack years in a three way analysis of covariance. A raised serum low density lipoprotein concentration was associated with accelerated progression of atherosclerosis only in men with higher than median serum copper concentrations (net difference $\mathbf{0 . 2 2} \mathrm{mm} ; \mathrm{p}<\mathbf{0 . 0 0 1}$ for two way interaction), and this synergism was even more pronounced in men with serum selenium concentrations below the median value (net difference $0.41 \mathrm{~mm} ; p=0.042$ for three way interaction).

Conclusion-These data provide evidence of a synergistic effect of copper (a pro-oxidant), a low serum concentration of selenium (a cofactor of an enzyme that scavenges free radicals), and low density lipoprotein cholesterol concentration in atherogenesis.
\end{abstract}

Kuopio Research Institute of Exercise Medicine, Kuopio, Finland

Kari Seppänen, MPH, chemist

Department of Chemistry, University of Kuopio Marjatta Kantola, MPH, chemist

Sirpa Suntioinen, MPH, chemist

Department of Community Health and General

Practice, University of Kuopio

Heikki Korpela, MD, assistant professor

Correspondence and requests for reprints to: Professor Salonen.

BMF 1991;302:756-60 factors affecting its oxidation should modify its association with the progression of the disease. There are, however, to our knowledge no previous studies of the association of pro-oxidants and antioxidants with progression of atherosclerosis and their effect on the impact of low density lipoprotein cholesterol on atherogenesis.

We have shown previously that a raised serum low density lipoprotein cholesterol concentration is associated with an accelerated increase of carotid artery wall (intima media) thickness. ${ }^{2}$ The purpose of the present study was to test the hypothesis that the atherosclerosis promoting effect of a raised low density lipoprotein cholesterol concentration would be enhanced in conditions that favour its oxidative modification - that is, in people with high copper and low selenium concentrations.

\section{Methods}

\section{STUDY POPULATION}

The Kuopio ischaemic heart disease risk factor study is a population study to investigate previously unestablished risk factors for ischaemic heart disease and extracoronary atherosclerosis. ${ }^{27}$ The study population comprises a stratified random $33 \%$ sample of men aged $42,48,54$, or 60 at examination who live in a geographically defined area in eastern Finland. ${ }^{7}$ The participation rate in the baseline examination was $84 \%$ in 1987.

Since February 1987 the men's carotid arteries have been assessed by ultrasonography by a physician (RS) as part of the study. The baseline examination also included assessment of smoking with a self administered questionnaire; measurement of height, weight, and blood pressure; haematological tests; and determination of serum cholesterol concentration in the main lipoprotein fractions.

In all, 146 men who underwent carotid ultrasonography during February to May 1987 or October to November 1987 were invited to be re-examined two years later. The follow up examination was carried out exactly (within two days) 24 months after the baseline examination in each subject. The sampling ratio in the groups of 48 and 54 year olds was threefold and in just the 60 years group fourfold compared with that in the 42 years group. Of the men invited, two had died, two were disabled, two had migrated abroad, four refused to participate, six could not be contacted, and two were excluded because their body mass index exceeded $35 \mathrm{~kg} / \mathrm{m}^{2}$. The remaining 128 men $(93 \%$ of those eligible) were reassessed by ultrasonography. Of these, complete baseline data on serum copper, selenium, and low density lipoprotein cholesterol concentrations were available for $126 \mathrm{men}$. The numbers of men in the four age groups were $10,33,35$, and 48 . The mean age at baseline of men who were re-examined was $54 \cdot 0$ years.

\section{ASSESSMENT OF ATHEROSCLEROSIS}

The details of the ultrasonographic scanning of carotid arteries have been presented previously. ${ }^{2}$ The ATL UM 4 Duplex Ultrasound System (Advanced Technology Laboratories, Bothel, Washington, United States) with a mechanical sector transducer with $10 \mathrm{MHz}$ transducer frequency in $\mathrm{B}$ mode and $5 \mathrm{MHz}$ in 
pulsed Doppler mode was used. The axial resolution of the system in B mode was approximately $0.3 \mathrm{~mm}$. The intima media thickness was measured from video recording of the entire scanning procedures by the scanning physician (RS). The reader was blinded with regard to the subject's identity and whether she was reading a baseline or a two year follow up recording. ${ }^{2}$ Three measurements of intima media thickness were carried out of the far wall of both the right and left common carotid artery at the site of the greatest intima media thickness. The mean of these six measurements was used in the present study.

The coefficient of variation over the three measurements for each artery, averaged for all subjects, was $2 \cdot 3 \%$ for the right common carotid artery and $2 \cdot 4 \%$ for the left artery. The reproducibility (measurement variability) of the measurement was studied by carrying out repeat scanning one week later than the baseline measurements in a randomly drawn subsample of 49 participants (out of 50 invited) in spring 1987. The rescanning was performed by the same sonographer (RS). The videotapes from the rescanning were read and the intima media thickness measurements done by another observer (JTS). The correlation between the intima media thickness in the first scan and in the second scan was 0.91 . The difference between the two measurements (means of three measurements) ranged from $-0.17 \mathrm{~mm}$ to $0.16 \mathrm{~mm}$, with a mean of $-0.03 \mathrm{~mm}$ and standard deviation (SD) of $0.09 \mathrm{~mm}$. Further details concerning the interobserver and intraobserver variability of this measurement are presented elsewhere. ${ }^{8}$

\section{RISK FACTOR MEASUREMENTS}

Measurements of the possible risk factors were carried out in the baseline examination in 1987. Blood samples were taken on the same day as the ultrasonographic assessment after fasting and abstinence from smoking for 12 hours and abstinence from alcohol for three days. Copper free needles and tubes were used for collecting and storing blood. The subjects rested in a supine position for 30 minutes before blood sampling. A tourniquet was not used.

The main lipoprotein fractions (very low density, low density, and high density) were separated weekly from unfrozen serum samples by ultracentrifugation and precipitation according to Carlson. ${ }^{9}$ The cholesterol content of all lipoprotein fractions was measured enzymatically by the cholesterol oxidase/peroxidaseamidopyrine method (Boehringer Mannheim). The between batch coefficient of variation during 1987-8 was $2 \cdot 2 \%$ for total cholesterol and $5 \cdot 2 \%$ for low density lipoprotein cholesterol $(n=76)$.

Serum copper and selenium concentrations were determined by atomic absorption spectrometry. Serum samples had been frozen for about two years before analysis. Seronorm (Nycomed, Oslo, Norway) control serum samples were included in all daily batches. For copper a Perkin-Elmer (Norwalk, Connecticut, United States) 306 atomic absorption spectrometer was used with a flame technique with standards made in 5\% glycerol. The between batch coefficient of variation was $4.0 \% \quad(n=12)$. Selenium concentration was measured with a Perkin-Elmer 5000 atomic absorption spectrophotometer HGA 500 by the graphite furnace technique with a Zeeman background correction and pyrolytically coated graphite tubes with a platform. The between batch coefficient of variation was $5 \cdot 1 \%$ $(\mathrm{n}=20)$. Plasma ascorbic acid concentrations were determined daily in unfrozen samples by high performance liquid chromatography. ${ }^{10}$ Blood leucocyte count was measured with the Coulter Counter Model Dn leucocyte counter.

The current number of cigarettes, cigars, and pipefuls of tobacco smoked daily; duration of regular smoking in years; history of myocardial infarction, angina pectoris, or other ischaemic heart disease; and the presence of hypertension and whether subjects were taking antihypertensive drugs were recorded by using a self administered questionnaire, which was checked by an interviewer. The medical history was also recorded in a further interview by a physician. The lifelong exposure to smoking (in cigarette pack years) was estimated as the product of years of smoking and the number of tobacco products smoked daily at the time of examination.

\section{STATISTICALMETHODS}

Analysis concerned the associations of baseline risk factor levels with the increase in intima media thickness at follow up two years later. The independent and joint contribution of risk factors to the increase was estimated and tested for significance by the statistical package for the social sciences stepwise least squares multivariate regression analysis. The proportion of change in intima media thickness after two years explained by the independent variables (risk factors) was estimated as the multiple correlation squared. The correction of regression coefficients for the attenuation due to the random intraindividual variability in the dependent variable was calculated by dividing them by the square root of the Pearson correlation between the baseline thickness and thickness after two years.

The variation in the mean increase of intima media thickness after two years between subgroups according to serum copper, selenium, and low density lipoprotein cholesterol concentrations was tested for significance by the statistical package for the social sciences analysis of covariance" for Vax computers. The covariate adjusted means were computed with the same software. The proportion of variance in the dependent variable attributable to each main effect and interaction was estimated by the squared $\eta$ coefficient (proportion of sum of squares for each term of the total sum of squares).

To enable a straightforward interpretation of analyses of higher order interactions the risk factors of interest (serum copper, selenium, and low density lipoprotein cholesterol concentrations) were dichotomised by using median values as cut off values. For serum low density lipoprotein cholesterol concentration the median value $(4.0 \mathrm{mmol} / \mathrm{l})$ coincided with the treatment limit proposed by expert groups of both the European Atherosclerosis Society ${ }^{12}$ and the American Heart Association. ${ }^{13}$ For serum selenium concentration the median $(1.39 \mu \mathrm{mol} / \mathrm{l})$ corresponded to the saturation threshold of the glutathione peroxidase enzyme.

\section{Results}

In the baseline examination the maximal intima media thickness in common carotid arteries ranged from $0.53 \mathrm{~mm}$ to $2.25 \mathrm{~mm}$ (mean $0.98 \mathrm{~mm}$ (SD $0.28 \mathrm{~mm})$ ). The two year change ranged from $-0.06 \mathrm{~mm}$ to $0.90 \mathrm{~mm}(0.11 \mathrm{~mm}(0.19 \mathrm{~mm}) ; 95 \%$ confidence interval 0.07 to $0 \cdot 14 \mathrm{~mm})$. Serum copper concentration ranged from $11 \cdot 2 \mu \mathrm{mol} / 1$ to $35 \cdot 1 \mu \mathrm{mol} / 1$ (mean $17 \cdot 3 \mu \mathrm{mol} / \mathrm{l}$ ) and serum selenium concentration from $1.00 \mu \mathrm{mol} / \mathrm{l}$ to $1.91 \mu \mathrm{mol} / \mathrm{l}$ (mean $1.46 \mu \mathrm{mol} / \mathrm{l}$ ). The increase in the maximal carotid intima media thickness after two years was larger with increasing age $(\mathrm{r}=0.248 ; \mathrm{p}=0.005)$. On the basis of age adjusted bivariate standardised regression coefficients the strongest determinants of increase of thickness in the present data were cigarette packs years $(p=0 \cdot 0006)$, serum low density lipoprotein cholesterol concentration, serum copper concentration, blood leucocyte count, serum selenium concentration, and plasma ascorbic acid concentration (see table I for coefficients).

Cigarette pack years correlated inversely with plasma 
ascorbic acid $(\mathrm{r}=-0.30)$ and serum selenium $(r=-0.25)$ concentrations. The mean plasma ascorbic acid concentration was $34.07 \mu \mathrm{mol} / 1$ in smokers and $49.97 \mu \mathrm{mol} / 1$ in non-smokers $(p=0.002)$. The mean serum selenium concentration was $1.41 \mu \mathrm{mol} / 1$ in smokers and $1.49 \mu \mathrm{mol} / 1$ in non-smokers $(p=0.046)$. Serum copper concentration was $5 \%$ higher in smokers than in non-smokers (not significant). Both serum copper $(r=0 \cdot 34)$ and low density lipoprotein cholesterol $(r=0 \cdot 19)$ concentrations correlated positively with blood leucocyte count.

With inclusion of cigarette pack years, in addition to age, in the regression models the regression coefficient for serum selenium concentration decreased by $27 \%$ and that for plasma ascorbic acid concentration by $49 \%$ (table I), indicating that the independent contributions of these antioxidants to the increase of intima media thickness was to some extent attributable to their association with smoking. The contribution of serum low density lipoprotein cholesterol concentration to the increase of thickness was reduced by $15 \%$ by including serum copper concentration in the model but was virtually unaffected by other risk factors.

The independent associations of serum copper $(\geqslant 17.6 \mu \mathrm{mol} / \mathrm{l} v<17.6 \mu \mathrm{mol} / \mathrm{l})$, selenium $(\geqslant 1.40 \mu \mathrm{mol} / \mathrm{l}$ $v<1.40 \mu \mathrm{mol} / \mathrm{l}$ ), and low density lipoprotein cholesterol concentrations $(\geqslant 4.0 \mathrm{mmol} / \mathrm{l} v<4.0 \mathrm{mmol} / \mathrm{l})$ and smoking (yes $v$ no) were analysed in a four way analysis of covariance, adjusting linearly for age in years. Men with a serum copper concentration $\geqslant 17.6 \mu \mathrm{mol} / \mathrm{l}$ had $2 \cdot 1$-fold $(p=0.008)$ age adjusted increase of intima media thickness compared with those with a lower concentration, smokers a $2 \cdot 1$-fold increase $(p=0 \cdot 007)$ compared with non-smokers, men with serum selenium concentration $<1.40 \mu \mathrm{mol} / \mathrm{l}$ a 1.8 -fold increase $(\mathrm{p}=0.021)$ compared with those with a higher concentration, and men with serum low density lipoprotein cholesterol concentration $\geqslant 4.0 \mathrm{mmol} / \mathrm{l}$ a $1 \cdot 7$-fold increase $(p=0.042)$ compared with those with a lower concentration.

As smoking did not modify the association of either serum copper, or selenium, or low density lipoprotein cholesterol concentration with progression of atherosclerosis, adjusted (for age and cigarette pack years) means of increase in maximal intima media thickness

TABLE I-Adjusted and unadjusted regression coefficients for increase in maximal common carotid intima media thickness after two years (in $0.1 \mathrm{~mm}$ ) and biological determinants

\begin{tabular}{lccc}
\hline & & & \\
& Unadjusted & Adjusted for age & $\begin{array}{c}\text { Adjusted for age and } \\
\text { cigarette pack years }\end{array}$ \\
\hline Serum copper $(\geqslant 17 \cdot 6 \mu \mathrm{mol} / \mathrm{l} v<17 \cdot 6 \mu \mathrm{mol} / \mathrm{l})$ & $1 \cdot 089^{\star \star}$ & $1 \cdot 014^{\star \star}$ & $0 \cdot 886^{\star \star}$ \\
Serum selenium $(\geqslant 1 \cdot 40 \mu \mathrm{mol} / \mathrm{l} v<1 \cdot 40 \mu \mathrm{mol} / \mathrm{l})$ & $-0.916^{\star \star}$ & $-0.815^{\star}$ & $-0 \cdot 597$ \\
Serum low density lipoprotein cholesterol $(\mathrm{mmol} / \mathrm{l})$ & $0 \cdot 526^{\star \star}$ & $0 \cdot 511^{\star \star}$ & $0.525^{\star \star \star}$ \\
Blood leucocyte count $\left(10^{\circ} / \mathrm{l}\right)$ & $0 \cdot 230^{\star}$ & $0 \cdot 250^{\star \star}$ & $0 \cdot 202^{\star}$ \\
Plasma ascorbic acid $(\mu \mathrm{mol} / \mathrm{l})$ & $-0.096^{\star}$ & $-0.086^{\star}$ & -0.044 \\
\hline
\end{tabular}

${ }^{\star} \mathrm{p}<0.05 ;{ }^{\star \star} \mathrm{p}<0.01 ;{ }^{\star \star \star} \mathrm{p}<0.001$

TABLE II - Mean increase in maximal carotid intima media thickness after two years ( $\mathrm{mm}$ ) (adjusted for age and cigarette pack years) according to baseline serum concentrations of copper, selenium, and low density lipoprotein cholesterol

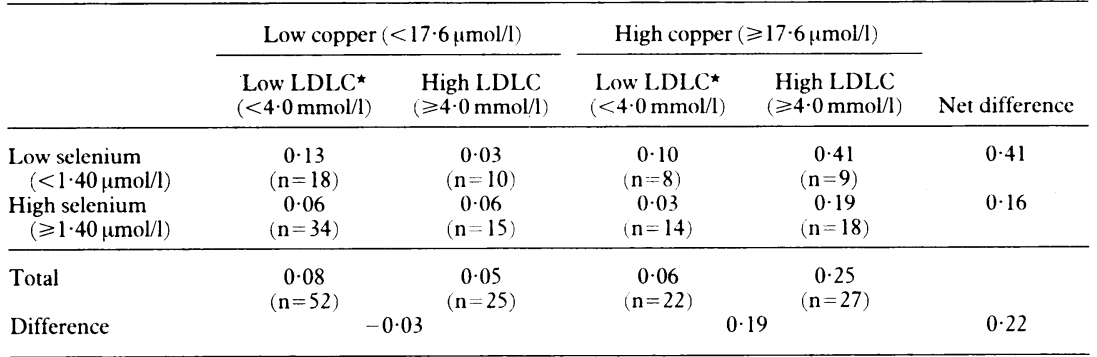

^LDLC $=$ low density lipoprotein cholesterol

Attributable proportions $\left(\eta^{\prime}\right)$ and significance of effect in three way analysis of covariance, adjusted for age $(p<0.001)$ and cigarette pack years $(p<0.001)$. Main effects: $0.037, p=0.010$ for copper; $0.024, p=0.035$ for selenium; and $0.025, p=0.032$ for low density lipoprotein cholesterol. Interactions: $0.086, p<0.001$ for copper and cholesterol; $p=0.962$ for selenium and cholesterol; $0.021, p=0.053$ for copper and selenium; and $0.023, p=0.042$ for copper and selenium and cholesterol.
TABLE III-Mean (95\% confidence interval) increase in maximal carotid intima media thickness after two years $(\mathrm{mm}$ ) (adjusted for age and cigarette pack years) according to serum copper and low density lipoprotein concentration

\begin{tabular}{lcc}
\hline & $\begin{array}{c}\text { Low LDLC } \\
(<4 \cdot 0 \mathrm{mmol} / \mathrm{l})\end{array}$ & $\begin{array}{c}\text { High LDLC } \\
(\geqslant 4 \cdot 0 \mathrm{mmol} / \mathrm{l})\end{array}$ \\
\hline $\begin{array}{c}\text { Low copper } \\
(<17.6 \mu \mathrm{mol} / \mathrm{l})\end{array}$ & $0.08(0.04$ to $0 \cdot 12)$ & $(\mathrm{n}=52)$ \\
$\begin{array}{c}\text { High copper } \\
(\geqslant 17.6 \mu \mathrm{mol} / \mathrm{l})\end{array}$ & $0.06 \begin{array}{c}(0.02 \text { to } 0 \cdot 10) \\
(\mathrm{n}=22)\end{array}$ & $\begin{array}{c}(0.02 \text { to } 0.08) \\
(\mathrm{n}=25)\end{array}$ \\
\hline
\end{tabular}

LDLC $=$ Low density lipoprotein cholesterol.

were also computed in a three way analysis of covariance (table II). The entire covariance model explained $37 \cdot 8 \%(42 \cdot 8 \%$ if corrected for random error in thickness change) of the change in thickness after two years. When blood leucocyte count was added as a third covariate the attributable fraction for serum copper decreased by $39 \%$ but remained significant $(p=0.043)$ and that for serum low density lipoprotein cholesterol reduced by $32 \%$ and lost its significance, whereas the impact of serum selenium concentration remained unchanged. The age and smoking adjusted difference in the increase of thickness in men with a low density lipoprotein cholesterol concentration $\geqslant 4.0 \mathrm{mmol} / \mathrm{l}$ compared with those with a lower concentration was $0.19 \mathrm{~mm}$ among those with high serum copper concentrations and $-0.03 \mathrm{~mm}$ in those with low serum copper concentrations, the net difference being $0.22 \mathrm{~mm}(95 \%$ confidence interval $0 \cdot 10$ to $0.34 \mathrm{~mm}$ ).

To illustrate further the interaction between copper and low density lipoprotein cholesterol table III presents the mean increase of intima media thickness adjusted for age and smoking according to serum copper and low density lipoprotein cholesterol concentrations. Raised serum low density lipoprotein cholesterol concentration was associated with accelerated progression of carotid atherosclerosis only in men with high serum copper concentration $(p<0.001$ for two way interaction). The mean adjusted increase in thickness was $0.25 \mathrm{~mm}$ in men with both high copper and high low density lipoprotein cholesterol concentrations and only $0.05 \mathrm{~mm}$ in those with a serum copper concentration below the median value (table III). This synergism was even more pronounced in men with low serum selenium concentrations $(\mathrm{p}=0.025$ for three way interaction). In addition, the association of serum copper concentration with the increase in thickness was stronger in men with low serum selenium concentrations ( $p=0.031$ for two way interaction).

Three variables - age, baseline maximal intima medi\& thickness, and serum low density lipoprotein cholesterol concentration-accounted for $25 \cdot 2 \%$ of the variation of the increase in maximal intima media thickness after two years in men with high (above median) serum copper concentration and only for $5.0 \%$ in men with low serum copper concentration. The variables age, cigarette pack years, serum low density lipoprotein cholesterol concentration and serum selenium concentration $(\geqslant 1.40 \mu \mathrm{mol} / 1 \mathrm{l}<1.40 \mu \mathrm{mol} / \mathrm{l})$ accounted for $36.7 \%$ of the change in thickness in men with a high copper concentration.

\section{Discussion}

We have previously observed an excess incidence of and mortality from ischaemic heart disease in eastern Finnish men and women with low serum selenium concentrations. ${ }^{14}$ The present data complement this finding by suggesting a mechanism through which a low selenium concentration could contribute to the development of ischaemic heart disease. In addition, the results of this study offer an explanation for the exceptionally high mortality from ischaemic heart disease in eastern Finnish men. In the Finnish cohorts 
of the seven countries study the softness and acidity of drinking water and its increased content of copper were associated with an excess 10 year mortality from coronary heart disease. ${ }^{15}$ The present findings help to explain the reported associations between soft, acidic drinking water and ischaemic heart disease.

Mean values for serum copper concentration between $12.7 \mu \mathrm{mol} / \mathrm{l}$ and $16.5 \mu \mathrm{mol} / 1$ have been reported in healthy men. ${ }^{16-18}$ The mean serum copper concentration in our study population was higher than that reported in other populations. Eastern Finland is a low selenium area with a high copper content in drinking water, $11^{519}$ and the availability of copper is enhanced by the acidity and softness of drinking water. ${ }^{20}$ Other sources of copper intake in Finland are water pipes in houses, which are most often made of copper. Acidic water dissolves copper from the pipes. In addition, the average serum cholesterol concentration in eastern Finnish men is among the highest in the world. ${ }^{21}$ Our findings suggest that these exposures may contribute synergistically to the high incidence of atherosclerotic vascular diseases in eastern Finland.

\section{PEROXIDATION}

A high selenium intake might reduce the prooxidant activity of copper by interfering with its absorption, by binding free copper, or by reacting with it to form chemically inactive compounds. ${ }^{22}$ Transition metals like copper are extremely good promoters of free radical reactions and lipid peroxidation. ${ }^{23}$ Copper is especially effective in promoting peroxidation of lipoproteins. ${ }^{624}$ The peroxidation of low density lipoprotein is thought to take place within the arterial wall rather than in the circulation. ${ }^{3}$ Lewis and Paton have proposed that copper facilitates the conversion of xanthine dehydrogenase to xanthine oxidase, which may promote the reduction of molecular oxygen to superoxide free radicals. ${ }^{25}$ Serum copper concentration has been shown to correlate positively with that of malondialdehyde, an index of lipid peroxidation. ${ }^{26}$

\section{SMOKING}

Cigarette smokers in our study population had lower plasma ascorbic acid and serum selenium concentrations than non-smokers. This finding agrees with previous ones. ${ }^{27-29}$ As in the second national health and nutrition examination survey, the inverse association between smoking and serum ascorbic acid concentrations persisted after adjustment for dietary ascorbic acid intake ${ }^{29}$; smoking seems to lower plasma ascorbic acid concentration. The high content of free radicals in cigarette smoke is a plausible biological explanation for the depletion of physiological antioxidants like ascorbic acid and selenium dependent glutathione peroxidase, and the atherogenesis promoting effect of smoking could be partly due to this. If this mechanism is of aetiological importance allowing for snoking in the statistical analysis would represent an overadjustment. Thus our analysis may be quite conservative. Also, we did not make corrections for the attenuation of either correlations or regressions due to the random intraperson variability over time in the risk factor measurements, which were carried out only once.

\section{BLOOD LEUCOCYTE COUNT}

As in our earlier analysis in a subset of subjects from the present study,' blood leucocyte count was an independent risk factor for the progression of atherosclerosis. An increased count has had in prospective population studies an independent, strong association with mortality from coronary heart disease and the risk of myocardial infarction. ${ }^{30}$ Monocytes, neutrophils, and intimal macrophages may oxidise low density lipoprotein by oxygen radicals, making it cytotoxic and chemotactic. ${ }^{363132}$ An increased production of oxygen radicals in leucocytes has been observed in hypercholesterolaemic subjects as compared with age matched subjects with normal cholesterol concentrations. ${ }^{33}$ An increase in the leucocyte count could be a consequence of activation of monocytes and neutrophils because of increased oxidative stress in the presence of high circulating low density lipoprotein and copper concentrations. The correlations of serum copper and low density lipoprotein cholesterol concentrations with blood leucocyte count in our data support this hypothesis. The association of serum copper concentration with atherogenesis and the excess atherogenesis promoting effect of raised low density lipoprotein concentration in men with high copper concentrations persisted even after adjustment for blood leucocyte count. This suggests that high serum copper concentrations were not merely a consequence of raised concentrations of acute phase proteins like caeruloplasmin but rather a causal factor.

\section{CONCLUSIONS}

The present data indicate that the atherogenesis promoting effect of raised serum low density lipoprotein cholesterol concentration is present only, or at least is stronger, in men with high serum copper concentrations, and this synergism is enhanced by a low selenium concentration. Furthermore, the findings suggest that high serum copper and low serum selenium concentrations are also independent risk factors for the progression of atherosclerosis. The impact of increased serum copper concentration may in part be mediated through or associated with leucocyte activation. Also, low plasma ascorbic acid concentration may be associated with accelerated progression of atherosclerosis, although this relation seems to be accounted for by smoking and serum selenium concentration. Our data provide additional evidence for the importance of oxidation of low density lipoprotein in the aetiology of atherosclerosis. If confirmed in larger prospective studies of the progression of atherosclerosis these findings imply that in preventing the progression of atherosclerosis, in addition to concentrating on lowering circulating low density lipoprotein cholesterol concentrations, attention should be paid to factors promoting and inhibiting the oxidation of low density lipoprotein.

1 Blankenhorn DH, Alaupovic P, Wickham E, Chin HP, Azen SP. Prediction of angiographic change in native human coronary arteries and aorta coronary angiographic change in native human coronary arteries and aorta coron

2 Salonen R, Salonen JT. Progression of carotid atherosclerosis and its determinants: a population based ultrasonography study. Atherosclerosis determinants: a population based ultrasonography study. Atherosclerosis $1990 ; 81: 33-40$.

3 Steinberg D, Parthasarathy S, Carew TE, Khoo JC, Witztum JL. Beyond cholesterol. Modifications of low-density lipoprotein that increase its atherogenicity. $N$ Engl f Med 1989;320:915-24.

4 Avogaro P, Bittolo Bon G, Cazzalato G. Presence of a modified low density lipoprotein in humans. Arteriosclerosis 1988;8:79-87.

5 Palinski W, Rosenfeld ME, Ylä-Herttuala S, et al. Low density lipoprotein undergoes oxidative modification in vivo. Proc Nall Acad Sci USA 1989;86: 1372-6.

6 Jürgens G, Hoff HF, Chisholm GM, Esterbauer H. Modification of human serum low density lipoprotein by oxidation-characterisation and pathophysiological implications. Chem Phys Lipids 1987;45:315-36.

7 Salonen JT. Is there a continuing need for longitudinal epidemiologic research - the Kuopio ischemic heart disease risk factor study. Ann Clin Res
(a) research - the Kuo
$1988 ; 20: 46-50$.

8 Salonen R, Haapanen A, Salonen JT. Measurement of intima-media thickness of common carotid arteries with high-resolution B-mode ultrasonography: inter-and intra-observer variability. Ultrasound Med Biol (in press

9 Carlson K. Lipoprotein fractionation. F Clin Pathol 1973;26(suppl 5):32-7.

10 Parviainen MT, Nyyssönen K, Pentilä IM, et al. A method for routine assay of plasma ascorbic acid using high-performance liquid chromatography. fournal of Liquid Chromatography 1986;9:2185.

11 SPSS-X user's guide. A complete guide to SPSS-X language and operations. 2nd ed. New York: McGraw-Hill, 1983.

12 Recognition and management of hyperlipidaemia in adults: a policy statement of the European Atherosclerosis Society. Eur Hear f 1988;9:571-600.

13 Report of the national cholesterol education program. Expert panel on detection, evaluation, and treatment of high blood cholesterol in adults. Arch Intern Med 1988:148:36-69.

14 Salonen JT, Alfthan G, Huttunen JK, Pikkarainen J, Puska P. Association between cardiovascular death and myocardial infarction and serum selenium between cardiovascular death and myocardial infarction and
in a matched-pair longitudinal study. Lancet 1982;ii:175-9.

15 Punsar S, Erametsä O, Karvonen MJ, Ryhänen A, Hilska P, Vornamo H. 
Coronary heart disease and drinking water. A search in two Finnish male cohorts for epidemiologic evidence of a water factor. 7 Chronic Dis $1975 ; 28: 259-87$

16 Hatano S, Nishi $Y$, Usui $T$. Copper levels in plasma and erythrocytes in healthy Japanese children and adults. Am 7 Clin Nutr 1982;35:120-6.

17 Kant AK, Moser-Veillon PB, Reynolds RD. Dietary intakes and plasma concentrations of zinc, copper, magnesium, and selenium of voung, middle aged and older men. Nutrition Research 1989;9:717-24.

18 Singh A, Dav BA, DeBold JE, Trostmann UH, Bernier LL, Deuster PA. Magnesium, zinc, and copper status of US navy SEAL trainees. A $m \mathcal{F}$ Clin Nutr 1989:49:695-700.

19 Hiisvirta L, Lehto J, Kumpulainen J, Koivistoinen P, Pitkänen L. Metals in main waters. Finn $\mathcal{F}$ Water Econ Hydr Agr Eng 1985;26:30

20 Mäkinen P. Problems of the water supply of rural areas caused by acidification and acid ground waters. Helsinki: Water and Environment 38, the National and acid ground waters. Helsinki. Water and Envire

21 WHO Monica Project. WHO Monica project: risk factors. In $f$ Epidemiol 1989; 18(suppl 1):S46-5

22 Shamberger RJ. Selenium. In: Frieden E, ed. Biochemistry of the essential ultratrace elements. New York: Plenum Press, 1984:201-37.

23 Halliwell B, Gutteridge JMC. Free radicals in biology and medicine. 2nd ed. Oxford: Clarendon Press, 1989

24 Esterbauer H, Strigl G, Puhl H, Rotheneder M. Continuous monitoring of in vitro oxidation of human low density lipoprotein. Free Radical Research Communicutions 1989;6:67-75.

25 Lewis KO, Paton A. Could superoxide cause cirrhosis? Lancel 1982; ; 188-9 26 Jeandel C, Nicolas MB, Dubois F, Nabet-Belleville F, Penin F, Guny G. Lipid peroxidation and free radical scavengers in Alzheimer's disease. (jecontolog 1989;35:275-82

27 Lloyd B, Lloyd RS, Clayton BE. Effect of smoking, alcohol, and other factors on the selenium status of a healthy population. 7 Epidemiol Community Health 1983;37:213-7.

28 Moore JA, Noiva R, Wells IC. Selenium concentrations in plasma of patient with arteriographically defined coronary atherosclerosis. Clin Chem 1984 30:1171-3.

29 Schectman $\mathrm{G}$, Byrd JC, Gruchow HW. The influence of smoking on vitamin $\mathrm{C}$ status in adults. Am F Public Health 1989;79:158-62.

30 Ernst E, Hammerschmidt DE, Bagge U, Matral A, Dormandy JA. Leucocytes and the risk of ischemic diseases. FAMA 1987;257:2318-24.

31 Cathcart MK, Morel DW, Chisolm GM. Monocytes and neutrophils oxidize low density lipoprotein making it cytotoxic. I Leukocyte Biol 1985;38: $342-50$.

32 Quinn MT, Parthasarathy S, Fong LG, Steinberg D. Oxidatively modified low density lipoproteins: a potential role in recruitment and retention of monocyte/macrophages during atherogenesis. Proc Natl Acad Sci 1987;84: 2995-8.

33 Ludwig PW, Hunninghake DB, Hoidal JR. Increased leucocyte oxidative metabolism in hyperlipoproteinaemia. Lancet 1982;i:348-50.

(Accepted l February 1991)

\section{Frequency of carriers of cystic fibrosis gene among patients with myeloid malignancy and melanoma}

\author{
N Warren, J A Holmes, L Al-Jader, \\ R R West, D C Lewis, R A Padua
}

University of Wales College of Medicine, Cardiff CF4 4XN

$\mathrm{N}$ Warren, BSC, research officer in surgery

J A Holmes, MRCP, lecturer in haematology

L Al-Jader, MB, clinical assistant in medical genetics

$\mathrm{R} R$ West, PHD, reader in epidemiology

D C Lewis, FRCS, research

fellow in surgery

R A Padua, PHD, senior

lecturer in haematology

Correspondence to:

Dr R A Padua, Leukaemia

Research Fund,

Preleukaemia Unit,

Department of

Haematology, University of

Wales College of Medicine, Cardiff CF4 $4 \mathrm{XN}$.

BMF 1991;302:760-1

Cystic fibrosis is an autosomal recessive disease with a prevalence of carriers of about $5 \%$ and an overall incidence in white populations of 1 in 2000 live births. The cystic fibrosis gene has been cloned and sequenced, and a deletion $(\Delta \mathrm{F} 508)$ that causes the loss of a phenylalanine residue at amino acid position 508 has been mapped.' This deletion accounts for $74 \%$ of carriers in Britain.?

In a preliminary report of an epidemiological survey of families affected by cystic fibrosis an association between putative carrier status for cystic fibrosis and leukaemia (most notably acute myeloid leukaemia) was found. ${ }^{3+}$

To test this association we studied the frequency of $\Delta$ F508 in DNA from patients with acute myeloid leukaemia, the myelodysplastic syndrome, and malignant melanoma (as a solid tumour control) and from normal subjects.

\section{Patients, methods, and results}

Normal DNA was obtained at random from healthy donors from the blood transfusion service. Donors were screened according to the blood service's protocols, which included an extensive questionnaire, interview by the attending doctor, and check of haemoglobin concentrations and blood pressure. These samples were not consecutive. Samples from patients with acute myeloid leukaemia and the myelodysplastic syndrome were obtained from the department of

Carriers of $\triangle F 508$ in patients with and without malignancy

\begin{tabular}{|c|c|c|c|c|}
\hline & \multirow{2}{*}{$\begin{array}{l}\text { No } \\
\text { studied }\end{array}$} & \multicolumn{2}{|c|}{ No of $\Delta F 508$ carriers } & \multirow{2}{*}{$\begin{array}{c}\text { Odds ratio } \\
\text { ( } 95 \% \text { confidence interval) }\end{array}$} \\
\hline & & Expected & Observed & \\
\hline \multicolumn{5}{|l|}{ Patients with: } \\
\hline Myelodysplastic syndrome & 159 & 6 & 7 & $0.89(0.28$ to 2.77$)$ \\
\hline Acute myeloid leukaemia & 137 & 5 & 7 & $1.04(0.33$ to 3.25$)$ \\
\hline Naevus & 20 & 1 & 1 & $1.01(0.12$ to 8.55$)$ \\
\hline Melanoma & 166 & 6 & $0 \dagger$ & $0(0$ to 0.64$)$ \\
\hline Normal subjects & 162 & 6 & $8 t$ & \\
\hline
\end{tabular}

^Using Cornfelds method.

tComparison of patients with melanoma and normal subjects, $\mathrm{p}=0 \cdot 007$ (Fisher's exact two tailed test). haematology and from those patients with melanoma from the department of surgery and subsequent follow up clinics. The patients were selected at random and the sample size was determined by the availabilty of material.

The samples were either peripheral blood, bone marrow, histological specimens, fresh washes of the buccal mucosa, or paraffin embedded tissue blocks. They were screened for $\Delta \mathrm{F} 508$ by using a modified polymerase chain reaction procedure and polyacrylamide gel electrophoresis. Direct sequencing of the products of the polymerase chain reaction confirmed the published sequences for the wild type and mutated alleles.

The table shows the results of the screening for the deletion. The expected number of carriers of $\Delta F 508$ were estimated on the basis of the putative gene frequency in the population, which is $74 \%$ of $1 / 20=1 / 27$. Most of the groups studied had the normal expected frequency for carriers. Except for patients with melanomas, the differences found were not significant.

Unexpectedly, no carriers were found among 166 patients with melanoma. This differed significantly from the eight carriers found among 162 normal subjects ( $p=0 \cdot 007$, Fisher's exact two tailed test). In 91 of the patients with melanomas the constitutional genotype was confirmed by analysis of tissue from adjacent skin, blood, or buccal mucosal cells. In a genetic survey of first and second degree relatives of patients with cystic fibrosis two skin cancers were found. Both of these were basal cell carcinomas not melanomas, although among the number of patients studied the expected frequency of melanoma was less than one $(3000 / 10000=0 \cdot 3)$.

\section{Comment}

This study shows that carriers of $\Delta \mathrm{F} 508$ may be protected from developing melanoma. The finding of a single carrier in the group with naevus suggests that cell lineage specificity is not a possible explanation for this finding. The case for leukaemias has yet to be proved: to reach significance with a carrier to noncarrier ratio of $2: 1$ roughly 600 patients in each leukaemic group would have to be analysed.

Carriers of one cystic fibrosis gene show no symptoms of the disease. This has led to the suggestion that heterozygosity for cystic fibrosis confers some form of biological advantage that has allowed the potentially lethal gene to be retained in the population at a high frequency. The incidence of melanoma in the United Kingdom, however, is 10 in 100000 , and therefore it does not seem that protection against only melanoma 